\title{
Feasibility and Safety of a Fold-Over Diverting Ileostomy Reversal After Rectal Cancer Surgery: Case-Matched Comparison to the Resection Technique
}

\author{
Jinock Cheong, Jeonghyun Kang, Im-Kyung Kim, Nam Kyu Kim, Seung-Kook Sohn, Kang Young Lee \\ Department of Surgery, Yonsei University College of Medicine, Seoul, Korea
}

Purpose: Compared to the stapling technique, the fold-over technique (FO) has the benefit of avoiding the sacrifice of the bowel segment. The aim of this study was to compare short-term outcomes between the FO and a conventional resection. Methods: Between June 2008 and March 2012, a total of 242 patients who underwent a diverting ileostomy reversal after rectal cancer surgery were selected. Among them, 29 patients underwent the FO. Using propensity scores to adjust for body mass index, previous abdominal surgery history, rectal cancer surgery type (open vs. minimally invasive), and reason for ileostomy (protective aim vs. leakage management), we created a well-balanced cohort by matching each patient who underwent the FO, as the study group, with two patients who underwent a stapled or a hand-sewn technique with bowel resection $(\mathrm{RE})$, as the control group $(\mathrm{FO}: \mathrm{RE}=1: 2)$. Morbidity and perioperative recovery were compared between the two groups.

Results: Twenty-four and forty-eight patients were allocated to the FO and the RE groups, respectively. The mean operation time was $91 \pm 26$ minutes in the FO group and $97 \pm 34$ minutes in the RE group $(\mathrm{P}=0.494)$. The overall morbidity rates were not different between the two groups $(12.5 \%$ in $\mathrm{FO}$ vs. $14.6 \%$ in $\mathrm{RE}, \mathrm{P}=1.000)$. The rate of postoperative ileus was similar between the two groups $(8.3 \%$ in FO vs. $12.5 \%$ in $\mathrm{RE}, \mathrm{P}=0.710)$. Although time to resumption of soft diet was shorter in the FO group than in the RE group, the lengths of hospital stay were not different.

Conclusion: The FO and the conventional resection have similar short-term clinical outcomes for diverting ileostomy reversal.

Keywords: Ileostomy; Ileostomy repair; Rectal neoplasms

\section{INTRODUCTION}

A diverting loop ileostomy may be performed during rectal cancer surgery for two main reasons. One reason is to protect the

Received: May 4, 2013 - Accepted: November 14, 2013

Correspondence to: Kang Young Lee, M.D.

Department of Surgery, Gangnam Severance Hospital, Yonsei University College of Medicine, 211 Eonju-ro, Gangnam-gu, Seoul 135-720, Korea Tel: +82-2-2019-3378, Fax: +82-2-3462-5994

E-mail: kylee117@yuhs.ac

This study was presented at the research forum of the Korean Society of Coloproctology, 46th Annual Meeting in April 2013, Gyeongju, Korea.

(c) 2014 The Korean Society of Coloproctology

This is an open-access article distributed under the terms of the Creative Commons Attribution NonCommercial License (http://creativecommons.org/licenses/by-nc/3.0) which permits unrestricted noncommercial use, distribution, and reproduction in any medium, provided the original work is properly cited. anastomosis site from leakage, or the "protective aim". An ileostomy is regarded as one of the most reliable means to reduce the severity of pelvic sepsis caused by anastomotic leakage $(\mathrm{AL})$, although whether or not it really reduces the AL rate is unclear [13]. The other reason is to save patients from the severe septic conditions caused by AL. Most patients with AL undergo a temporary loop ileostomy with an eventual reversal.

A diverting ileostomy reversal is accomplished by either a handsewn or stapled anastomosis after resection of a segment of the small bowel [4]. Stapled anastomosis has gained popularity for its simplicity and acceptable clinical outcomes [5-7]; however, the extra equipment is more expensive, and patients may not able to afford it. In this situation, a hand-sewn technique without resection of the small bowel, called the fold-over technique, may be another option for ileostomy reversal [8].

The purpose of this study was to compare the clinical outcomes 
between the fold-over technique (FO) and the stapled or a stapled or a hand-sewn technique with bowel resection (RE) for ileostomy reversal after rectal cancer surgery.

\section{METHODS}

Between June 2008 and March 2012, a total of 242 patients who underwent a diverting ileostomy reversal after initial rectal cancer surgery were selected. Baseline characteristics included age, sex, body mass index (BMI), smoking habits, history of previous abdominal surgery, American Society of Anesthesiologists (ASA) grade, previous rectal cancer operation type (open vs. minimally invasive surgery), tumor height of the rectal cancer, and reason for the ileostomy (protective aim vs. leakage management). Ileostomy reversal techniques were as follows: FO (Fig. 1) and a stapled or a hand-sewn technique with bowel RE. Among the initially enrolled patients, 29 patients underwent the FO technique. The other patients underwent the RE technique.

Using propensity scores to adjust for BMI, previous abdominal
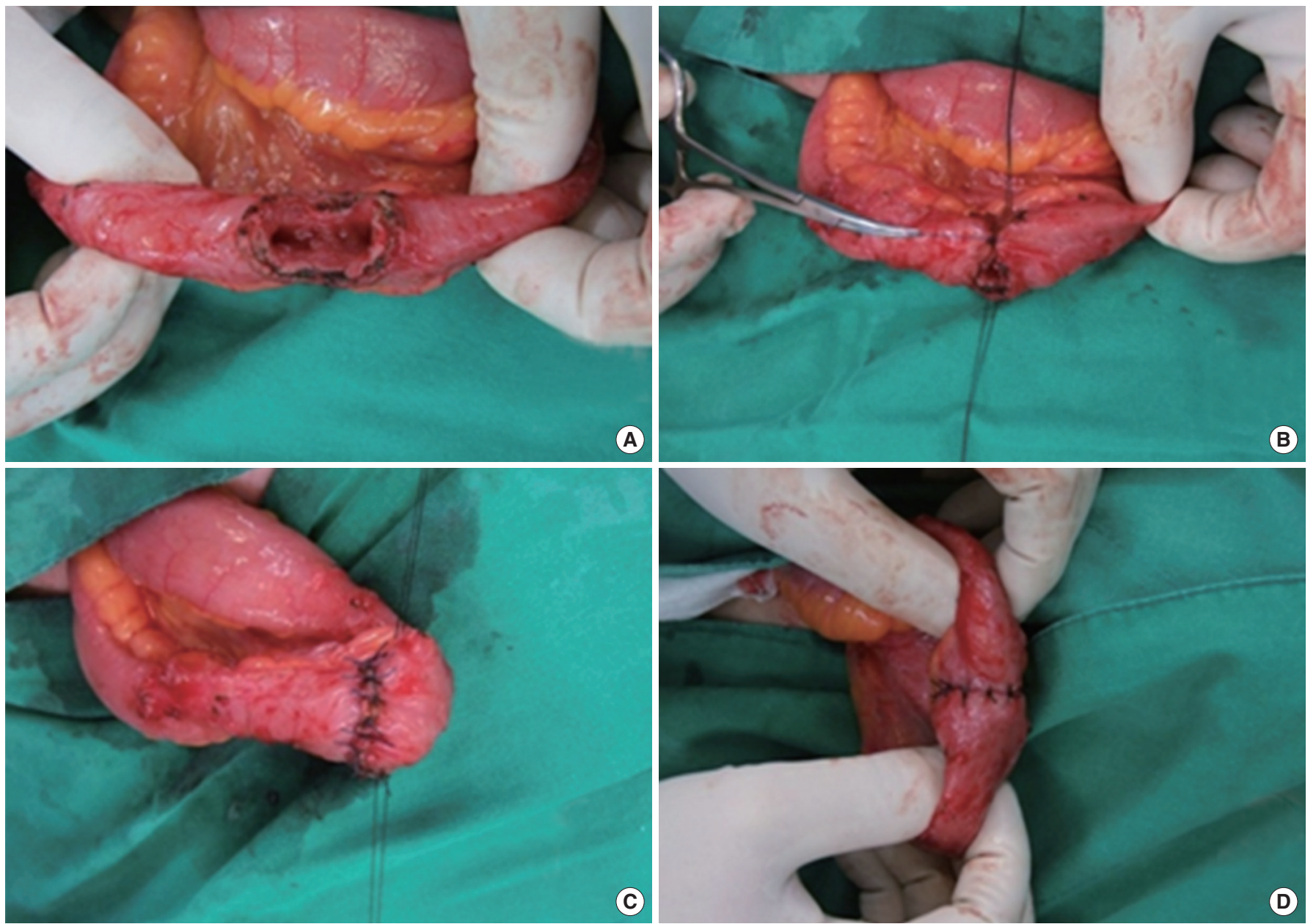

surgery history, previous rectal cancer operation type, and reason for the ileostomy, we created a well-balanced cohort by matching each patient who underwent the FO, as the study group, with two patients who underwent the RE, as the control group (FO:RE = 1:2).

Postoperative outcomes included the time interval between ileostomy formation and reversal, the operative time, complications (ileus/obstruction, wound infection, and reoperation) and recovery outcomes (time to first flatus, time to soft diet intake and length of hospital stay). Postoperative complications were defined as adverse events that occurred within 30 days of surgery. Complications were diagnosed and categorized according to the patients' symptoms with the aid of laboratory and radiologic evaluations in order to confirm clinical suspicions. Ileus/obstruction was defined as any condition involving abdominal distension or pain with nausea or vomiting, which was confirmed with a plain abdominal X-ray. Morbidity and perioperative recovery were compared between the two groups.

All statistical analyses were performed using SAS 9.1.3 (SAS In-

Fig. 1. (A-D) Fold-over technique for ileostomy reversal. 
Table 1. Comparison of the patients' baseline characteristics between the two groups

\begin{tabular}{lccc}
\hline Variable & $\begin{array}{c}\text { Fold-over group } \\
(\mathrm{n}=24)\end{array}$ & $\begin{array}{c}\text { Resection group } \\
(\mathrm{n}=48)\end{array}$ & P-value \\
\hline Gender & & & 0.116 \\
$\quad$ Male & $21(87.5)$ & $34(70.8)$ & \\
$\quad$ Female & $3(12.5)$ & $14(29.2)$ & \\
Age (yr) & $59.5 \pm 10.7$ & $60.9 \pm 10.7$ & 0.610 \\
Body mass index (kg/m²) & $23.1 \pm 2.8$ & $23.7 \pm 2.1$ & 0.391 \\
Smoking habit & & & 0.366 \\
$\quad$ Smoker & $9(37.5)$ & $13(27.1)$ & \\
PAS & $3(12.5)$ & $7(14.6)$ & $1.000^{\mathrm{a}}$ \\
ASA grade & & & $0.840^{\mathrm{a}}$ \\
$\quad 1$ & $15(62.5)$ & $25(52.1)$ & \\
2 & $8(33.3)$ & $20(41.7)$ & \\
3 & $1(4.2)$ & $3(6.3)$ & \\
Rectal-cancer's surgery type & & & $1.000^{\mathrm{a}}$ \\
\hline Open & $1(4.2)$ & $3(6.3)$ & \\
MIS & $23(95.8)$ & $45(93.8)$ & \\
Rectal-cancer's tumor height (cm) & $6.7 \pm 1.6$ & $7.3 \pm 2.7$ & 0.200 \\
Reason for ileostomy & & & 0.864 \\
Protective aim & $15(62.5)$ & $29(60.4)$ & \\
Leakage management & $9(37.5)$ & $19(39.6)$ & \\
\hline
\end{tabular}

Values are presented as number (\%) or mean \pm standard deviation. PAS, previous abdominal surgery history; ASA, American Society of Anesthesiologists; MIS, minimally invasive surgery.

aFisher exact test.

stitute Inc., Cary, NC, USA) and IBM SPSS ver. 20.0 (IBM Co., Armonk, NY, USA). Categorical variables were analyzed using the chi-square test, and continuous variables were analyzed using the Student t-test. $\mathrm{P}<0.05$ was considered statistically significant.

\section{RESULTS}

Of 242 patients, 24 and 48 were allocated to the $\mathrm{FO}$ and the RE groups, respectively. There were no significant differences in gender, age, BMI, smoking habits, previous abdominal surgery history, ASA grade, previous rectal cancer operation type, tumor height, or reason for the ileostomy between the two groups (Table 1). The time interval between ileostomy formation and reversal was longer in the FO group than in the RE group (226.0 days vs. 174.4 days, $\mathrm{P}=0.038$ ). There was no difference in mean operative times for stoma closure between the two techniques. The overall rates of postoperative complications were $12.5 \%$ in the FO group and $14.6 \%$ in the $\mathrm{RE}$ group $(\mathrm{P}=1.000)$. One patient in the $\mathrm{RE}$ group underwent a reoperation due to obstruction from a severe stricture at the anastomosis site on postoperative day seven. The
Table 2. Postoperative morbidity and recovery outcomes

\begin{tabular}{lccc}
\hline Variable & $\begin{array}{c}\text { Fold-over group } \\
(\mathrm{n}=24)\end{array}$ & $\begin{array}{c}\text { Resection group } \\
(\mathrm{n}=48)\end{array}$ & P-value \\
\hline $\begin{array}{l}\text { Time interval between ileostomy } \\
\text { formation and closure (day) }\end{array}$ & $226.0 \pm 91.6$ & $174.4 \pm 100.5$ & 0.038 \\
$\begin{array}{l}\text { Operative time (min) } \\
\text { Complications, } \mathrm{n}(\%)\end{array}$ & $91.4 \pm 26.7$ & $96.9 \pm 34.5$ & 0.494 \\
$\quad$ Overall & $3(12.5)$ & $7(14.6)$ & $1.000^{\mathrm{a}}$ \\
Ileus/obstruction & $2(8.3)$ & $6(12.5)$ & $0.710^{\mathrm{a}}$ \\
Wound infection & $1(4.2)$ & $1(2.1)$ & $1.000^{\mathrm{a}}$ \\
$\quad$ Reoperation & $0(0)$ & $1(2.1)$ & $1.000^{\mathrm{a}}$ \\
Recovery & & & \\
$\quad$ Time to first flatus (day) & $2(1-8)$ & $2(1-6)$ & 0.707 \\
Time to soft diet intake (day) & $3(2-14)$ & $4(2-8)$ & $<0.001$ \\
Length of hospital stay (day) & $5(3-16)$ & $5(4-21)$ & 0.154 \\
\hline
\end{tabular}

Values are presented as mean \pm standard deviation or median (range) unless otherwise indicated.

aFisher exact test.

rates of ileus/obstruction and wound infection were similar between the two groups. Although the time to soft diet intake was shorter in the FO group than in the RE group, the lengths of hospital stay were not different between the two groups (Table 2).

\section{DISCUSSION}

This study shows that the fold-over technique and the conventional resection have similar short-term clinical outcomes for a diverting ileostomy reversal after treatment of rectal cancer. A diverting ileostomy reversal is considered to be a simple and safe procedure; however, the overall morbidity following closure of a diverting ileostomy has been reported to be is $17.3 \%-33 \%$ and the mortality to be $0.4 \%[9,10]$. An ileostomy reversal may be performed using either a hand-sewn or a stapled technique [4]. Another issue is whether to cut the short opening segment of the small bowel. Leung et al. [5] reported no significant differences in short-term outcomes between the hand-sewn or the stapled technique. Luglio et al. [8] noted that the fold-over technique was associated with a shorter operative time, a lower morbidity rate and a faster recovery outcomes compared to the end-to-end, handsewn anastomosis (EE). They also reported that the fold-over technique had an overall morbidity rate and recovery outcomes that were similar to those of a stapled side-to-side anastomosis (ST), although the postoperative ileus rate was lower in the ST group than in the fold-over technique group. Considering all these results, they suggest that the ST may be preferable to the EE when a bowel resection at the ileostomy site is necessary because the shorter hospital stay compensates for the increased cost of the stapler. When a bowel resection is not necessary, the fold-over technique provides acceptable outcomes because the intact mesenteric 
side of the bowel maintains an adequate blood supply.

Our study revealed that the morbidity rates were not different between the FO and the RE groups. With respect to postoperative ileus, there was no difference between the two groups. Although the time to initiating soft diet was faster in the FO group, the lengths of hospital stay were similar between the two groups. In a subset analysis among the resection group, there were no differences in postoperative morbidity and recovery outcomes between the hand-sewn group and the stapled group (data not shown). These clinical outcomes confirmed previous findings about the FO and the RE techniques.

In some studies, the stapled technique was favored because it reduced the overall length of hospital stay [6]. However, the cost may differ according to each nation's socioeconomic status. Although we did not perform a cost analysis in our study, in our judgment, treatment for patients in the FO group may cost less than treatment for patients in the RE group.

The main limitation of this study was its retrospective design. Selection of the FO or the RE technique was determined by the surgeon's preference. Therefore, selection bias may have affected the comparison of surgical techniques. To reduce selection bias, before the analysis, we controlled factors affecting the surgical difficulty of ileostomy repair. We used a propensity score, including BMI, previous abdominal surgery history, rectal cancer operation type (open vs. minimally invasive), and reason for the ileostomy (protective aim vs. leakage management), to select a well-balanced cohort in each of the two groups.

In conclusion, the fold-over technique showed no significant differences compared to the conventional resection for ileostomy reversal. Considering the low cost of the FO technique, it should be considered a useful technique for ileostomy reversal.

\section{CONFLICT OF INTEREST}

No potential conflict of interest relevant to this article was reported.

\section{REFERENCES}

1. Boccola MA, Lin J, Rozen WM, Ho YH. Reducing anastomotic leakage in oncologic colorectal surgery: an evidence-based review. Anticancer Res 2010;30:601-7.

2. Matthiessen P, Hallbook O, Rutegard J, Simert G, Sjodahl R. Defunctioning stoma reduces symptomatic anastomotic leakage after low anterior resection of the rectum for cancer: a randomized multicenter trial. Ann Surg 2007;246:207-14.

3. Karanjia ND, Corder AP, Bearn P, Heald RJ. Leakage from stapled low anastomosis after total mesorectal excision for carcinoma of the rectum. Br J Surg 1994;81:1224-6.

4. Hull TL, Kobe I, Fazio VW. Comparison of handsewn with stapled loop ileostomy closures. Dis Colon Rectum 1996;39:1086-9.

5. Leung TT, MacLean AR, Buie WD, Dixon E. Comparison of stapled versus handsewn loop ileostomy closure: a meta-analysis. J Gastrointest Surg 2008;12:939-44.

6. Hasegawa H, Radley S, Morton DG, Keighley MR. Stapled versus sutured closure of loop ileostomy: a randomized controlled trial. Ann Surg 2000;231:202-4.

7. Wong KS, Remzi FH, Gorgun E, Arrigain S, Church JM, Preen M, et al. Loop ileostomy closure after restorative proctocolectomy: outcome in 1,504 patients. Dis Colon Rectum 2005;48:243-50.

8. Luglio G, Pendlimari R, Holubar SD, Cima RR, Nelson H. Loop ileostomy reversal after colon and rectal surgery: a single institutional 5-year experience in 944 patients. Arch Surg 2011;146:1191-6.

9. Chow A, Tilney HS, Paraskeva P, Jeyarajah S, Zacharakis E, Purkayastha $S$. The morbidity surrounding reversal of defunctioning ileostomies: a systematic review of 48 studies including 6,107 cases. Int J Colorectal Dis 2009;24:711-23.

10. Garcia-Botello SA, Garcia-Armengol J, Garcia-Granero E, Espi A, Juan C, Lopez-Mozos F, et al. A prospective audit of the complications of loop ileostomy construction and takedown. Dig Surg 2004;21:440-6. 